\title{
A survey of dairy calf management practices among farms using manual and automated milk feeding systems in Canada
}

\author{
Catalina Medrano-Galarza, ${ }^{*}{ }^{1}$ Stephen J. LeBlanc, ${ }^{*} \dagger$ Trevor J. DeVries, $\dagger \ddagger$ Andria Jones-Bitton, ${ }^{*}$ \\ Jeffrey Rushen,§ Anne Marie de Passillé,§ and Derek B. Haley* ${ }^{1}$ \\ *Department of Population Medicine, Ontario Veterinary College, \\ †Campbell Centre for the Study of Animal Welfare, and \\ łDepartment of Animal Biosciences, University of Guelph, Guelph, Ontario N1G 2W1, Canada \\ §Faculty of Land and Food Systems, University of British Columbia, Agassiz, British Columbia V6T 1Z4, Canada
}

\begin{abstract}
Dairy calves in North America traditionally are housed individually and fed by manual milk feeding (MMF) systems with buckets or bottles. Automated milk feeders (AMF) allow for more natural milk feeding frequencies and volumes, and calves are usually housed in groups. The objectives of this study were to (1) determine the prevalence of various milk-fed calf management and feeding practices and (2) compare these practices between dairy farms using MMF and AMF systems. A national online survey was performed from January to May 2015 to quantify management practices for the care of milk-fed dairy calves in Canada. A total of 670 responses were received ( $6 \%$ of all dairy farms in Canada). Among respondents, $16 \%$ used AMF and $84 \%$ used MMF. Seventy percent of the farms using AMF had freestall barns compared with only $48 \%$ of those using MMF. A greater proportion of AMF farms (30\%) also had automatic milking systems (AMS) compared with MMF farms (8\%). Among tiestall farms, a herd size of $>80$ milking cows was associated with having an AMF [odds ratio $(\mathrm{OR})=3.8 ; 95 \%$ confidence interval (CI): 1.6-11.4]. For freestall or bedded-pack farms, a herd size of $>80$ milking cows $(\mathrm{OR}=3.5 ; 95 \%$ CI: 1.8-6.6), having an AMS (OR $=3.1 ; 95 \%$ CI: 1.6-5.7), and use of cow brushes (OR $=3.1 ; 95 \%$ CI: $1.3-6.9$ ) were associated with having an AMF. Calves fed with AMS typically were housed in groups of 10 to 15 , whereas almost $76 \%$ of the farms with MMF housed calves individually. Although both AMF and MMF farms fed similar amounts of milk in the first week of life $($ median $=6 \mathrm{~L} / \mathrm{d})$, the cumulative volume fed in the first 4 wk differed significantly, with a median of 231 versus $182 \mathrm{~L}$ for AMF and MMF, respectively. Median
\end{abstract}

Received November 7, 2016.

Accepted April 8, 2017.

${ }^{1}$ Corresponding authors: cmedrano@uoguelph.ca and dhaley@ uoguelph.ca peak milk allowance was higher for AMF than for MMF (10 vs. $8 \mathrm{~L} / \mathrm{d}$, respectively). In summary, farms using AMF were larger, provided more milk to calves, and used more automation in general (i.e., in other areas of their operation). These data provide insights into calf-rearing practices across Canada and into how the use of AMF is affecting calf feeding and management on dairy farms.

Key words: dairy calf, management, automation, manual feeding

\section{INTRODUCTION}

Under conventional dairy systems in North America, most calves are individually housed and fed by manual milk feeding (MMF) systems through open buckets or bottles (Vasseur et al., 2010; USDA, 2016). In addition, dairy farms traditionally use restricted milk feeding plans, providing calves $10 \%$ of their BW in milk per day (Khan et al., 2011). These practices may allow for early weaning of calves by promoting early solid feed intake and reduction of rearing costs. The latter often is achieved by feeding restricted volumes of milk with restricted frequency (i.e., 2 meals per day; Khan et al., 2011). In the United States, the USDA's National Animal Health Monitoring System (USDA, 2016) found that $85 \%$ of dairies housed calves individually, $72 \%$ fed milk through open buckets, and $56 \%$ offered $4.7 \mathrm{~L}$ of milk/d or less to calves. Similarly, in Canada, $88 \%$ of farms in Quebec housed calves individually and $92 \%$ used open buckets, and the median amount of milk offered to calves was $5.5 \mathrm{~L} / \mathrm{d}$ (Vasseur et al., 2010).

Research from Canada, Denmark, and the United Kingdom has shown that restricted milk feeding and the lack of socialization associated with individual housing constrain the welfare of calves by limiting their expression of natural behaviors such as sucking for milk and social play (de Passillé et al., 1993; Jensen et al., 2015), subjecting calves to hunger and frustration (Thomas et al., 2001; Borderas et al., 2009; Rosenberger et al., 
2017) and impairing calf health (Appleby et al., 2001; McCorquodale et al., 2013). These common practices also do not realize calf growth potential (Miller-Cushon et al., 2013; Rosenberger et al., 2017), and although other factors such as genetics play a role (Davis Rinker et al., 2011), these practices may also reduce future milk production performance (Soberon et al., 2012; Soberon and Van Amburgh, 2013; Gelsinger et al., 2016).

Automated milk feeders (AMF) are an alternative to MMF systems. They involve the use of computercontrolled systems and typically are associated with housing calves in groups while providing individualized feeding of milk (Jensen and Weary, 2013). They provide for more natural and efficient rearing of calves than MMF systems by allowing larger amounts of milk to be fed several times a day, resulting in improved calf welfare (Käck and Ziemerink, 2010; Jensen and Weary, 2013). Nonetheless, good management practices are required when using AMF because there is some potential for intensive group housing to have detrimental effects on calf health and welfare if not managed properly (Svensson and Liberg, 2006). For example, when calves are housed in large groups, risk of respiratory disease and mortality rate increase (Svensson et al., 2003, 2006; Svensson and Liberg, 2006) and feeding patterns of newly introduced calves are altered (Jensen, 2003).

Information on current calf management practices is necessary to assess changes in practices and the effect of potential on-farm interventions and adoption of technology to improve calf welfare and performance on dairy farms. Therefore, the objectives of this study were to (1) determine the prevalence of various milk-fed calf management and feeding practices and (2) compare these practices between dairy farms using MMF and AMF systems.

\section{MATERIALS AND METHODS}

A cross-sectional online survey of dairy farmers across Canada was conducted from January 2015 to the end of May 2015. The survey was administered via a webbased survey platform (FluidSurveys; SurveyMonkey, San Mateo, CA). An email with an introductory letter and the hyperlink to the survey was sent by the 2 dairy herd management centers in Canada (CanWest DHI, Guelph, Ontario; Valacta, Sainte-Anne-de-Bellevue, Quebec) to dairy producers registered in their databases (implied sampling frame $=\sim 80 \%$ of dairy producers in Canada). Additionally, the survey was advertised in the Dairy Farmers of Canada (Ottawa, Ontario) internal newsletter, the Dairy Research Cluster blog (https:// dairyresearchblog.ca), and 2 dairy cattle magazines distributed across Canada (Milk Producer and Le Producteur de Lait Québécois) and on social media (e.g.,
Facebook). This study was reviewed and approved by the University of Guelph Research Ethics Board (REB no. 14JN025).

\section{Sample Size Estimation}

The WINPEPI statistical program (version 11.62; Abramson, 2011) was used to estimate the number of farms required to describe population attributes $(\mathrm{n}=$ $11,962)$ such as mean daily milk allowance and proportion of farms housing calves in groups. Using an assumed standard deviation of $2.5 \mathrm{~L} / \mathrm{d}$ and an acceptable error of $0.2 \mathrm{~L} / \mathrm{d}$ for daily milk allowance, the required sample size was 574 farms for a confidence level of $95 \%$. Using an assumed proportion of farms housing calves in groups of 0.3 and an acceptable error of 0.035 , the required sample size was 685 farms.

\section{Collection and Description of Data}

The survey was designed in consultation with a panel of experts (11 dairy specialists from academia, industry, and government) and was pretested by 8 dairy producers, an equal number of which used MMF or AMF systems. The final version of the survey (available in English and French) consisted of 2 questionnaires with closed- (i.e., multiple choice, ranking, and 5-point Likert scales) and open-ended questions; 1 questionnaire was for producers using MMF systems (i.e., milk offered via open bucket or teat-bottle, bucket, or milk bar), and 1 questionnaire was for producers using AMF (i.e., computer-controlled systems).

Both questionnaires started and ended with 2 identical sections: generalities of the farm (e.g., location, breed of cattle, type of housing) and demographics of the personnel responsible for calves (e.g., age and education level). At the end of the first section, producers were asked what type of automated devices they had on their farm, and based on their answer for AMF (i.e., yes-no question) they were directed to the corresponding questionnaire. We collected data on management and calf care during calves' first days of life (i.e., cow-calf separation, colostrum management) and management and care during the entire milk feeding period. Both questionnaires gathered the same type of information (thus allowing comparisons), but questions were worded differently to be consistent with the milk feeding system being used. In addition, a set of questions was tailored to capture information that was unique to AMF (e.g., the feeder setup and the process of introducing calves to the AMF). Full-length questionnaires are available online as supplemental data (total number of questions: $\mathrm{MMF}=70, \mathrm{AMF}=86$; https://doi.org/10.3168/jds.2016-12273). 
No survey question was required to be answered; therefore, the total number of responses varied by question, as noted later. Although the survey could be answered in a median time of 30 min (based on the completion times of the pretesting), the web-based platform allowed producers to save and return to their answers any time before submitting their survey.

\section{Data Management and Analysis}

Data were exported from the web-based survey platform into Microsoft Excel (Microsoft Corp., Redmond, WA) for data cleaning and screening. A total of 837 producers clicked the survey link and consented to complete the questionnaire. After screening the data, 167 producers were removed for the following reasons: no answers were provided to any of the questions ( $\mathrm{n}=$ 121); it was not clear whether the farms were Canadian $(\mathrm{n}=9)$; homemade AMF were used, and it was not clear whether these were computer-controlled systems $(\mathrm{n}=9)$; herd size was very small (2 and 5 milking cows, $\mathrm{n}=2$; producers had just sold their milk quota); and farm was located in the United States $(\mathrm{n}=1)$. In addition, 25 producers participated twice; the response with the highest number of questions answered was kept.

All data were analyzed with SAS version 9.3 (SAS Institute Inc., Cary, NC). Descriptive statistics calculated included percentages, $95 \%$ confidence intervals (CI), medians, and 25th and 75th percentiles. The Anderson-Darling test was used to test normality of continuous variables. Chi-squared (or Fisher's exact) and Wilcoxon two-sample (with Hodges-Lehmann estimation of the median of the differences with 95\% CI) tests were used to evaluate differences in categorical and continuous variables, respectively, between farms with AMF and MMF systems. When no differences between farms with AMF and MMF were found, the overall percentages or medians are presented.

For the variable cow barn type (housing for milking cows), bedded-pack and freestall barns were grouped into a single category due to a low number of observations in the bedded-pack category, leaving cow barn type as a dichotomous variable (tiestall vs. loose housing). A variable for geographical region was created by grouping provinces into 3 categories - western region (provinces of British Columbia, Alberta, Saskatchewan, and Manitoba), Ontario region, and Quebec and Atlantic region (provinces of Quebec, New Brunswick, Prince Edward Island, Nova Scotia, and Newfoundland and Labrador) - based on geographic location or dairy herd management center to have a balanced number of observations in each region. The association of having an AMF with farm size, producer age, producer sex, number of personnel looking after calves, and use of other technology devices (e.g., cow activity monitors, automated feed pushers, and automated milking systems; AMS) was evaluated using logistic regression (PROC LOGISTIC in SAS) with geographic region included as a fixed effect to adjust for the effect of region. Two separate models were fit-one for tiestall farms and another for loose-housing barns - to help control for confounding caused by inherent differences in milking systems and the use of other technologies between both housing types (e.g., few tiestall barns had activity monitors; AMS was present exclusively in loose-housing barns). Explanatory variables with an association $(P<0.20)$ with the outcome in univariable models were offered to the multivariable model. The linearity assumption for the variable farm size could not be fulfilled; therefore, it was dichotomized based on the average milking herd size for Canada (80 milking cows; Cyprien Awono, Agriculture and Agri-Food Canada, Ottawa, Ontario, Canada; personal communication). Correlation between predictors was assessed using Spearman correlation coefficients $\left(r_{s}>0.8\right)$. A variable was considered a confounder if its removal caused $>20 \%$ change in the coefficient (on the logarithmic odds scale) of another variable in the model. Any nonsignificant variables $(P>0.05)$ were checked for confounding by removing them from the full model using backward elimination, starting with the variable with the largest $P$-value. All 2 -way interactions were tested between variables that remained in the model. The Pearson goodness-of-fit test was used to evaluate whether the models fit the data.

Differences between AMF and MMF farms in the volume of milk (L/d per calf) offered to calves by week of life were evaluated using linear regression (PROC MIXED in SAS) with geographic region as a fixed effect and accounting for repeated measures within farm. Specifically, the model included the fixed effects of week, milk feeding system (AMF vs. MMF), and week by milk feeding system interaction. The unstructured variance-covariance matrix structure was used for the random effect of farm on the basis of best fit according to Akaike information criterion (Dohoo et al., 2009). Daily milk allowance was compared only during the first 4 wk of life; after this point, the length of the milk feeding period varied between farms, making comparisons difficult.

\section{RESULTS}

\section{General Description of Producers and Farms}

A total of 670 dairy producers across Canada were included in the analysis (6\% of all dairy farms in Canada; CDIC, 2015). Of the respondents, 16\% (95\% 
Table 1. Percentage (95\% CI) of participant farms using automated milk feeders (AMF, $\mathrm{n}=105)$ and manual milk feeding (MMF, $\mathrm{n}=565$ ) systems for raising dairy calves from an online questionnaire completed by 670 dairy producers in Canada

\begin{tabular}{|c|c|c|c|c|c|}
\hline Demographics & $\mathrm{AMF}$ & MMF & $P$-value & $\begin{array}{l}\text { All participant } \\
\text { farms }\end{array}$ & $\begin{array}{c}\text { Canadian } \\
\text { statistics, }{ }^{1} \%\end{array}$ \\
\hline Language & & & 0.59 & & \\
\hline English (vs. French) & $77(68-85)$ & $80(76-83)$ & & $79(76-82)$ & - \\
\hline Sex & & & 0.81 & & \\
\hline Male (vs. female) & $70(61-79)$ & $72(68-75)$ & & $72(68-75)$ & - \\
\hline Participant age, yr & & & 0.42 & & \\
\hline$<25$ & $8(3-15)$ & $8(6-10)$ & & $8(6-10)$ & 15 \\
\hline $25-34$ & $24(16-33)$ & $27(23-31)$ & & $27(23-30)$ & 15 \\
\hline $35-44$ & $30(22-40)$ & $20(17-24)$ & & $22(19-25)$ & 20 \\
\hline $45-54$ & $26(18-35)$ & $30(26-34)$ & & $29(26-33)$ & 37 \\
\hline$>54$ & $12(7-20)$ & $15(12-18)$ & & $14(12-17)$ & 28 \\
\hline Geographic region & & & 0.29 & & \\
\hline Western $^{2}$ & $21(14-30)$ & $23(20-27)$ & & $23(20-26)$ & 12 \\
\hline Ontario & $49(39-59)$ & $48(44-52)$ & & $48(44-52)$ & 33 \\
\hline Quebec and $\mathrm{AP}^{3}$ & $30(22-40)$ & $29(25-33)$ & & $29(26-33)$ & 55 \\
\hline
\end{tabular}

${ }^{1}$ Source for age distribution: Canadian Dairy Information Centre - Census 2011 (CDIC, 2011; dairy farm operators: $\mathrm{n}=22,055)$. Source for province distribution: CDIC (2015; dairy farms: $\mathrm{n}=11,683)$.

${ }^{2}$ British Colombia, Alberta, Saskatchewan, and Manitoba.

${ }^{3} \mathrm{AP}=$ Atlantic provinces (New Brunswick, Prince Edward Island, Nova Scotia, and Newfoundland and Labrador).

CI: $13-19 ; \mathrm{n}=105)$ used AMF to raise calves and $84 \%$ (95\% CI: 81-87; $\mathrm{n}=565$ ) used MMF systems. The majority of respondents were from Ontario (48\%) followed by Quebec and Atlantic provinces (29\%). More than three-fourths of the respondents $(79 \%)$ completed the survey in English. Approximately $72 \%$ of respondents were male, and the age category most common among participants was 45 to 54 years. Table 1 shows demographics by type of farm based on milk feeding system.

Overall, the average reported herd size was 90 milking cows (range: 17-2,800). Farms with AMF had a significantly larger herd size compared with farms with MMF systems (median of the difference $=35$ milking cows; $95 \%$ CI: $25-45 ; P<0.001$; Table 2). Holstein was the most common breed among all farms (96 and $93 \%$ of farms with AMF and MMF, respectively). The proportion of freestall barns for housing milking cows was significantly higher among farms using AMF compared with farms using MMF (Table 3). A higher proportion of farms with AMF had adopted AMS and other types of technology compared with farms using MMF (Table $3)$.

\section{Factors Associated with Having an AMF}

Farms with more than 80 milking cows in either tie stalls or loose housing were more likely to have an AMF (Table 4). Additionally, loose-housing farms using an AMS and using cow brushes were more likely to have an AMF for calves. Age of the producer was a factor associated with having an AMF only in tiestall farms, where producers aged 55 years or above had lower odds of using an AMF (Table 4).

\section{Newborn Calf and Colostrum Management}

Overall, $59 \%$ of farms reported disinfecting the newborn's navel (95\% CI: 55-63; n $=640$ ); there was no difference between farms with AMF and MMF ( $P$ $=0.26)$. The majority of farms with AMF and MMF

Table 2. Number of milking cows on farms using automated milk feeders (AMF) and manual milk feeding (MMF) systems for raising dairy calves from an online questionnaire completed by 670 dairy producers in Canada

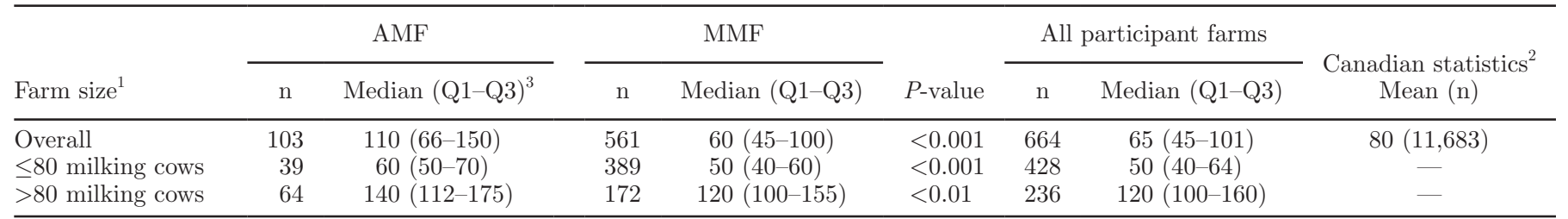

${ }^{1}$ Dichotomization of farm size based on the average farm size of Canadian dairy farms.

${ }^{2}$ Source: Cyprien Awono, Agriculture and Agri-Food Canada, Ottawa, Ontario, Canada; personal communication.

${ }^{3} \mathrm{Q} 1=25$ th percentile; $\mathrm{Q} 3=75$ th percentile. 
separated the calf from the dam within $24 \mathrm{~h}$ after birth (97\% of farms; $95 \%$ CI: 96-99; $\mathrm{n}=630 ; P=0.15$ ); however, a smaller proportion of farms with MMF (86\%; 95\% CI: 83-89) reported separation within $12 \mathrm{~h}$ compared with farms with AMF (98\%; 95\% CI: 93-100; $P$ $<0.001)$. Similarly, the proportion of farms separating the calf from the dam within $2 \mathrm{~h}$ after birth was lower for farms with MMF (51\%; 95\% CI: 47-55) than AMF (63\%; $95 \%$ CI: $53-73 ; P=0.03)$.

No differences were found in the timing of first colostrum feeding after birth between farms with AMF and MMF $(P=0.87)$; most farms reported giving the first meal of colostrum within the first $6 \mathrm{~h}$ after birth $(87 \%$; $95 \%$ CI: $84-89 ; \mathrm{n}=639)$. There was no difference $(P$ $=0.08$ ) in the proportion of farms feeding colostrum through a teat (either teat bottle or teat bucket) between farms with AMF and farms with MMF (82\%; 95\% CI: $79-85 ; \mathrm{n}=659$ ). The proportion of farms feeding colostrum exclusively through an open bucket differed between farms (AMF: 1\%; 95\% CI: 0-6; MMF: $8 \% ; 95 \%$ CI: 6 to $11 ; P<0.01)$. The proportion of farms feeding colostrum strictly through an esophageal tube did not differ between farms with AMF and MMF (8\%; 95\% CI: $6-10 ; \mathrm{n}=659 ; P=0.29)$.

There was no significant difference $(P>0.1)$ between farms with AMF and MMF regarding the amount of colostrum fed to calves in the first $12 \mathrm{~h}$ of life. Half of the farms reported giving calves 4 to $5 \mathrm{~L}$ of colostrum in the first $12 \mathrm{~h}$ of life (51\%; 95\% CI: $47-55 ; \mathrm{n}=649)$; $30 \%$ gave $6 \mathrm{~L}$ or more (95\% CI: $26-33 ; \mathrm{n}=649)$, whereas $14 \%$ reported giving $3 \mathrm{~L}$ or less $(95 \% \mathrm{CI}$ : $11-16 ; \mathrm{n}=$
649). Ad libitum colostrum was given on $2 \%$ of farms (95\% CI: $1-3 ; \mathrm{n}=649$ ). The evaluation of colostrum quality did not differ between AMF and MMF farms; only $23 \%$ of all farms reported always evaluating the quality of colostrum (95\% CI: 20-26; $\mathrm{n}=642$ ). Nevertheless, the evaluation of colostrum quality was done subjectively by looking at color and consistency on $44 \%$ of all farms, whereas the use of a colostrometer or a refractometer was reported by 30 and $18 \%$ of all farms, respectively. Newborn calf and colostrum management practices are summarized in Supplemental Table S1 (https://doi.org/10.3168/jds.2016-12273).

\section{Housing of Calves During the Milk Feeding Period}

Housing practices during the milk feeding period differed between farms with AMF and farms with MMF. The proportion of farms housing calves in groups was higher among farms with AMF $(P<0.001)$. Milk-fed calves on all AMF farms $(\mathrm{n}=105)$ were all group housed (no farm exclusively used an AMF for individually housed calves during the whole milk feeding period - i.e., calf rail). In contrast, $76 \%$ of farms using MMF systems housed milk-fed calves individually $(95 \%$ CI: $72-80 ; \mathrm{n}=526)$. The median age of introduction to a group (and to the AMF, for AMF farms) differed ( $P$ $<0.001$ ) between farms with MMF systems (median: $60 \mathrm{~d}$ of age; 25 th -75 th percentiles: $28-74 \mathrm{~d}, \mathrm{n}=475$ ) and farms with AMF (median: 5 d of age; 25th-75th percentile: $3-7 \mathrm{~d} ; \mathrm{n}=93$ ), with an estimated median of the differences of $54 \mathrm{~d}$ (95\% CI: 51-56).

Table 3. Percentage $(95 \%$ CI) of farms using automated milk feeders (AMF, $\mathrm{n}=105)$ and manual milk feeding $(\mathrm{MMF}, \mathrm{n}=565)$ systems for raising dairy calves from an online questionnaire completed by 670 dairy producers in Canada

\begin{tabular}{|c|c|c|c|c|c|}
\hline Farm descriptor & $\mathrm{AMF}^{1}$ & $\mathrm{MMF}^{2}$ & $P$-value & $\begin{array}{l}\text { All participant } \\
\text { farms }\end{array}$ & $\begin{array}{c}\text { Canadian } \\
\text { statistics, }{ }^{3} \%\end{array}$ \\
\hline Cow barn type & & & $<0.001$ & & \\
\hline Bedded pack & $6(3-6)$ & $4(2-6)$ & & $4(3-6)$ & \\
\hline Tiestall & $25(17-34)$ & $50(46-54)$ & & $46(42-50)$ & 71 \\
\hline Access to pasture allowed & $14(8-23)$ & $26(23-30)$ & 0.012 & $24(21-28)$ & - \\
\hline Milking system type & & & $<0.001$ & & \\
\hline \multicolumn{6}{|l|}{ Devices at the farm } \\
\hline Activity monitors & $63(53-72)$ & $32(29-36)$ & $<0.001$ & $37(33-41)$ & - \\
\hline Automated manure scrapers & $69(60-78)$ & $39(35-44)$ & $<0.001$ & $44(40-48)$ & - \\
\hline Automated feed pushers & $17(2-26)$ & $7(5-10)$ & $<0.001$ & $9(7-11)$ & - \\
\hline Cow brushes & $70(61-79)$ & $36(32-40)$ & $<0.001$ & $42(38-45)$ & - \\
\hline Automated grain feeder for cows & $22(15-31)$ & $24(21-28)$ & 0.621 & $24(21-28)$ & - \\
\hline
\end{tabular}

\footnotetext{
${ }^{1}$ Except for milking system type, where $\mathrm{n}=104$.

${ }^{2}$ Except for milking system type, where $\mathrm{n}=564$.

${ }^{3} \mathrm{n}=8,389$; CDIC (2015).

${ }^{4}$ Producers who had used AMF in the past but switched back to MMF systems.
} 
For farms using group housing, group size and maximum age difference between calves were greater on farms with AMF compared with farms with MMF ( $P$ $<0.001)$. Among farms with AMF $(\mathrm{n}=86), 58 \%(95 \%$ CI: 47-69) housed calves in groups of a maximum of 10 to $15,25 \%$ (95\% CI: $16-35)$ housed calves in groups of no more than 9, $14 \%$ (95\% CI: 7-23) housed a maximum of 16 to 20 calves, and 3\% (95\% CI: $1-10)$ housed a maximum of 21 to 40 calves per group. Among farms with MMF and group housing $(\mathrm{n}=125), 26 \%(95 \%$ CI: 18-34) housed calves in pairs, $64 \%$ (95\% CI: $55-72)$ housed calves in groups of 3 to 9, $8 \%$ (95\% CI: 4-14) housed a maximum of 10 to 15 calves per group, and $2 \%$ (95\% CI: $0.2-6)$ housed a maximum of 16 to 20 calves.

Maximum age difference between calves housed in groups was higher among farms with AMF compared with farms with MMF systems $(P<0.001)$. The most commonly reported age difference for AMF farms $(\mathrm{n}=$ 88 ) was 3 to $4 \mathrm{wk}$ ( $48 \%$ of the farms; $95 \%$ CI: $37-59$ ) followed by $7 \mathrm{wk}$ or more $(25 \%$; $95 \%$ CI: $16-35)$. For MMF farms $(\mathrm{n}=122)$, the most common age difference was 2 wk or less (54\% of the farms; 95\% CI: 45-63) followed by 3 to 4 wk (32\%; 95\% CI: 24-41).

Indoor housing was the most common type of housing used among the farms surveyed. A higher proportion $(P<0.001)$ of indoor housing was used on farms using AMF (98\%; 95\% CI: 92-100) compared with farms using MMF systems (70\%; 95\% CI: 66-74). There was no difference in the type of bedding material used in winter or summer between farms with AMF and farms with MMF systems; straw was the most commonly used material (winter: $82 \%$; $95 \%$ CI: 80-85; summer: $73 \%$; 95\% CI: 70-77). Other materials

Table 4. Final logistic regression models evaluating factors associated with having an automated milk feeder for raising milk-fed dairy calves with geographic region as fixed effect to adjust for region effects ${ }^{1}$

\begin{tabular}{|c|c|c|c|c|c|c|}
\hline \multirow[b]{2}{*}{ Model and variable } & \multirow[b]{2}{*}{ Coefficient } & \multirow[b]{2}{*}{$\mathrm{SE}$} & \multirow[b]{2}{*}{$\mathrm{OR}^{2}$} & \multicolumn{2}{|c|}{$95 \% \mathrm{CI}^{3}$} & \multirow[b]{2}{*}{$P$-value } \\
\hline & & & & LCL & UCL & \\
\hline \multicolumn{7}{|l|}{ Model 1: tiestall farms ${ }^{4}$} \\
\hline Intercept & -2.11 & 0.40 & - & - & - & - \\
\hline \multicolumn{7}{|l|}{ Farm size } \\
\hline$\leq 80$ milking cows & Referent & 0 & - & - & - & \\
\hline$>80$ milking cows & 0.67 & 0.28 & 3.81 & 1.26 & 11.48 & 0.02 \\
\hline \multicolumn{7}{|l|}{ Age of producer, yr } \\
\hline$>54$ & Referent & 0 & - & - & - & \\
\hline$<25$ & 0.54 & 0.57 & 5.38 & 0.49 & 59.11 & \\
\hline $25-34$ & 0.67 & 0.40 & 6.18 & 0.71 & 53.98 & \\
\hline $35-44$ & 1.04 & 0.63 & 8.91 & 1.04 & 76.25 & \\
\hline $45-54$ & -1.11 & 0.63 & 1.04 & 0.12 & 12.09 & 0.04 \\
\hline \multicolumn{7}{|l|}{ Geographic region } \\
\hline Western $^{5}$ & Referent & - & - & - & - & \\
\hline Quebec and Atlantic ${ }^{6}$ & -0.28 & 0.35 & 0.65 & 0.12 & 3.52 & \\
\hline Ontario & 0.12 & 0.37 & 0.97 & 0.17 & 5.49 & 0.65 \\
\hline \multicolumn{7}{|c|}{ Model 2: loose-housing farms ${ }^{7}$} \\
\hline Intercept & -1.45 & 0.23 & - & - & - & - \\
\hline \multicolumn{7}{|l|}{ Farm size } \\
\hline$\leq 80$ milking cows & Referent & 0 & - & - & - & \\
\hline$>80$ milking cows & 0.62 & 0.16 & 3.47 & 1.82 & 6.62 & $<0.001$ \\
\hline \multicolumn{7}{|c|}{ Automatic milking system } \\
\hline No & Referent & 0 & - & - & - & \\
\hline Yes & 0.56 & 0.16 & 3.07 & 1.65 & 5.72 & $<0.001$ \\
\hline \multicolumn{7}{|l|}{ Cow brushes } \\
\hline No & Referent & 0 & - & - & - & \\
\hline Yes & 0.56 & 0.21 & 3.08 & 1.37 & 6.93 & $<0.01$ \\
\hline \multicolumn{7}{|l|}{ Geographic region } \\
\hline Western $^{5}$ & Referent & - & - & - & - & \\
\hline Quebec and Atlantic $^{6}$ & 0.67 & 0.25 & 3.65 & 1.58 & 8.42 & \\
\hline Ontario & -0.04 & 0.19 & 1.79 & 0.94 & 3.39 & $<0.01$ \\
\hline
\end{tabular}

${ }^{1}$ Separate models were constructed for tiestall farms $(\mathrm{n}=308)$ and loose-housing farms $(\mathrm{n}=354)$.

${ }^{2}$ Odds ratio for having an automated milk feeder.

${ }^{3}$ Confidence interval for the odds ratio, lower confidence limit (LCL), and upper confidence limit (UCL).

${ }^{4}$ Pearson goodness of fit test: $\chi^{2}=20.4, P=0.25$.

${ }^{5}$ British Colombia, Alberta, Saskatchewan, and Manitoba.

${ }^{6}$ New Brunswick, Prince Edward Island, Nova Scotia, and Newfoundland and Labrador.

${ }^{7}$ Pearson goodness of fit test: $\chi^{2}=20.2, P=0.12$. 
used for bedding were sawdust (winter: $16 \%$; summer: $24 \%$ ), peat moss (winter: $16 \%$; summer: $24 \%$ ), sand (winter: $0.2 \%$; summer: $2 \%$ ), and dried manure (winter and summer: $0.3 \%$ ). Housing practices are summarized in Supplemental Table S2 (https://doi.org/10.3168/ jds.2016-12273). Among farms using AMF, 50\% (95\% CI: 39-60; $\mathrm{n}=95)$ renovated the existing calf barn, 41\% (95\% CI: 31-52) built a new calf barn, and $9 \%$ (95\% CI: 4-17) neither renovated nor built a new barn to accommodate calves in groups and install the AMF.

\section{Calf Feeding During the Milk Feeding Period}

Type of Milk Fed. There were differences $(P<$ 0.001 ) in the main type of milk fed to calves between farms with AMF ( $\mathrm{n}=93)$ and MMF systems $(\mathrm{n}=525)$. Milk replacer was the main type of milk used among AMF farms (89\%; 95\% CI: 81-95), whereas only $40 \%$ of MMF farms gave milk replacer to calves (95\% CI: 36-44). Among MMF farms, 36\% (95\% CI: 32-41) used saleable milk and 20\% (95\% CI: 17-24) used waste milk (i.e., nonsaleable milk from sick or antibiotic-treated cows). In comparison, among AMF farms, $5 \%$ (95\% CI: 2-12) used saleable milk and $4 \%$ (95\% CI: $1-11)$ used waste milk. Only 2\% (95\% CI: $0-6)$ and $4 \%$ (95\% CI: 2-5) of AMF and MMF farms, respectively, reported using a combination of salable and waste milk.

Among farms mainly using whole or waste milk, pasteurization of milk was implemented in a higher $(P=$
0.002) proportion of AMF farms (44\%; 95\% CI: 14-79) compared with MMF farms (7\%; 95\% CI: 4-10). Acidification did not differ between AMF and MMF farms $(P=0.32)$; only $3 \%$ of farms in total $(\mathrm{n}=617)$ acidified milk or milk replacer (95\% CI: 2-5). Practices regarding milk type fed to calves on AMF and MMF farms is summarized in Supplemental Table S3 (https://doi. org/10.3168/jds.2016-12273).

Daily Milk Allowance. Figure 1 shows the distribution of the daily milk volumes fed by week and type of milk feeding system. Overall, the cumulative volume of milk fed to calves during their first 4 wk of life differed $(P<0.001)$ between farms with AMF (median: 231 L; 25th-75th percentiles: 203-287; $\mathrm{n}=79$ ) and farms with MMF (median: $182 \mathrm{~L}$; 25th-75th percentiles: $154-224 ; \mathrm{n}=523$ ), with an estimated median of the differences of $56 \mathrm{~L}$ (95\% CI: 42-70). In multivariable analysis, daily milk allowance per calf by week was higher (wk 1: $P<0.01$; wk 2 to $4: P<0.001$ ) on AMF farms compared with MMF farms and peaked higher on AMF farms $(P<0.001)$.

Method of Feeding Milk. The majority of farms using AMF had 1 feeder (86\%; 95\% CI: 78-92; $\mathrm{n}=95$ ); $11 \%$ (95\% CI: $5-19)$ had 2 feeders, $2 \%$ (95\% CI: $0.3-7$ ) had 3 feeders, and 1\% (95\% CI: 0-6) had 6 feeders. Two feeding stations (each placed in a separated pen) per feeder was the most common setup among the surveyed farms ( $65 \%$ of the farms; $95 \%$ CI: $55-75 ; \mathrm{n}=92$ ). One feeding station per feeder was the setup for $31 \%$

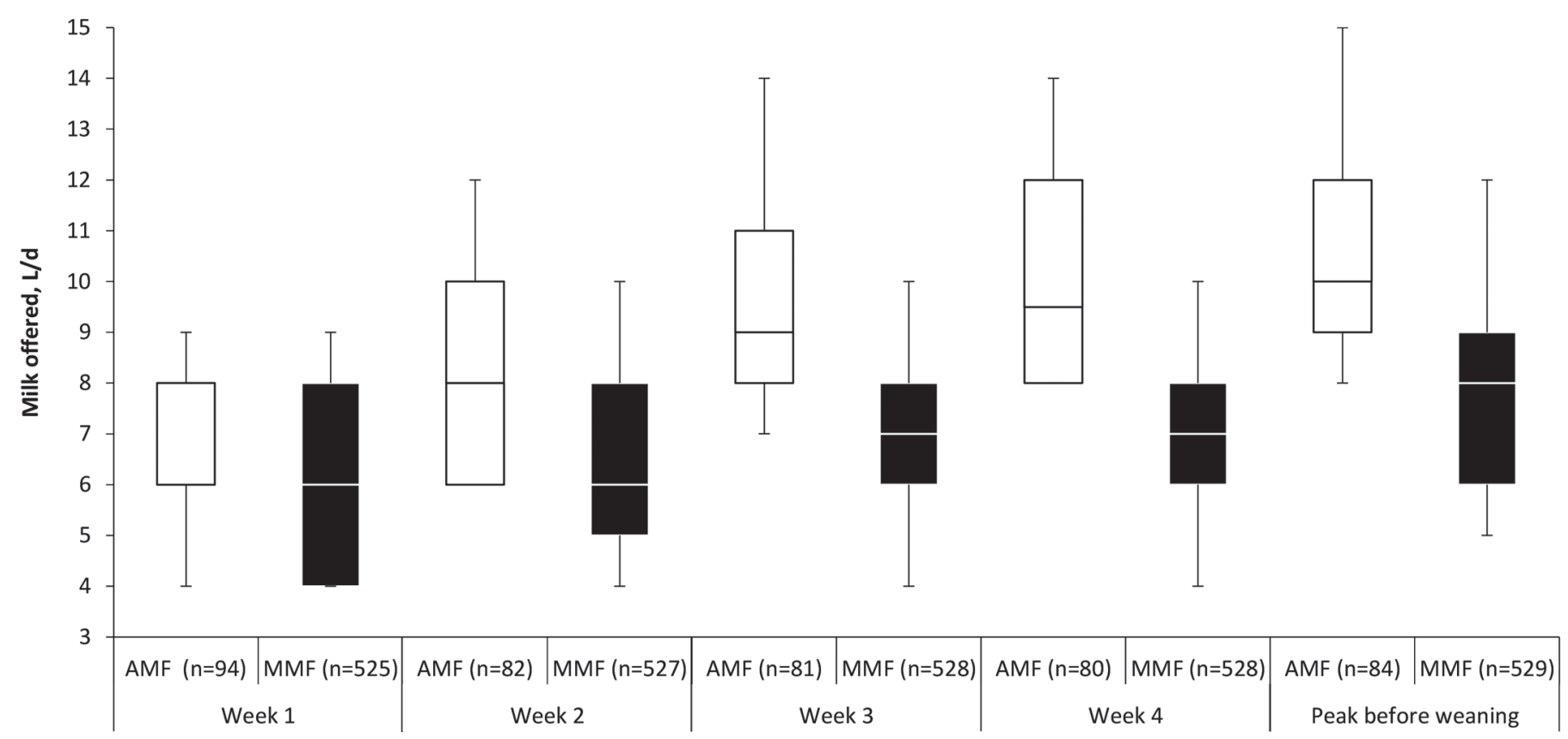

Figure 1. Distribution of daily amount of milk offered to calves by week of age during the first 4 wk of life and the peak amount offered before starting weaning for farms with automated milk feeders (AMF) or with manual milk feeding (MMF) systems. Median = line within the box; 25 th and 75 th percentiles = box part of the plot; 10 th and 90 th percentiles $=$ ends of the whiskers. 
of the farms (95\% CI: 21-41), whereas 2\% (95\% CI: 0.3-8) had 3 feeding stations per feeder and 1\% (95\% CI: 0-6) had 4 feeding stations per feeder. For those farms with 1 feeder supplying 2 or more feeding stations in separate pens, only 19\% (95\% CI: 10-31) had simultaneous feeding (i.e., 2 calves drinking at the same time from 2 different feeding stations), and 47\% (95\% CI: 34-60) did not have a simultaneous feeding but had activated the priority mode, which was set mainly based on calf age (i.e., younger calves had priority over older calves to drink first), pen (i.e., a specific feeding station had priority over the others), or level of milk consumption (i.e., calves with a low consumption had priority to drink first). Among all farms using AMF (n $=97$ ), 67\% (95\% CI: 57-76) had a feeder from Förster Technik (Engen, Germany) for group-housed calves, $24 \%$ (95\% CI: 16-33) used an Urban feeder (Rombouts, Salford, Ontario, Canada), 6\% (95\% CI: 2-13) used a Holm and Laue feeder (Holm and Laue GmbH and Co. KG, Westerrönfeld, Germany), and 3\% (95\% CI: 1-9) used an Uddermatic milk feeding system (Uddermatic, Alma, Ontario, Canada). Only 1 farm reported having a Förster Technik feeder for individually housed calves (calf rail feeding system), which was used during the first days of life before introducing calves to the group pen with an AMF. The earliest year of implementation of AMF among the surveyed farms was 2003; the greatest number of respondents implemented AMF in 2011.

Within farms feeding milk manually, 53\% (95\% CI: $48-57 ; \mathrm{n}=531$ ) used teats (bottles, teat buckets, or milk bars) to feed calves for at least the first 2 mo of life, whereas 36\% (95\% CI: 32-40) fed milk through open buckets and 11\% (95\% CI: 8-14) implemented a mix of teats and open buckets to feed milk. Among the latter, $60 \%$ of farms (95\% CI: 45-74) reported feeding milk through a teat only for the first 2 wk of life, $24 \%$ (95\% CI: 13-38) used teats for the first $3 \mathrm{wk}$ of life, $10 \%$ (95\% CI: 3-22) used teats only for the first month of life, and $6 \%$ (95\% CI: 1-17) used teats only for the first 5 to 6 wk of life. Most MMF farms (86\%; $95 \%$ CI: $82-89 ; \mathrm{n}=526)$ fed calves 2 times/d. Only $10 \%(95 \%$ CI: 8-13) fed calves 3 times/d, whereas $1 \%$ fed calves 4 times/d (95\% CI: 0.2-2); 3\% (95\% CI: 2-5) reported feeding calves ad libitum, although their maximum milk allowance ranged from 6 to $12 \mathrm{~L} / \mathrm{d}$. Method of feeding milk on AMF and MMF farms is summarized in Supplemental Table S3 (https://doi.org/10.3168/ jds.2016-12273).

Solid Feed and Water. There were no differences between AMF and MMF farms $(\mathrm{n}=610 ; P>0.1)$ in the proportion of farms that reported allowing milk-fed calves to access starter grain (97\%; 95\% CI: 95-98), hay $(67 \% ; 95 \%$ CI: $63-70)$, TMR (8\%; 95\% CI: $6-11)$, or water $(91 \%$; 95\% CI: 88-93). Age at access to different solid feeds and water is described in Table 5 . The proportion of farms allowing ad libitum access to starter was higher $(P<0.01)$ among AMF farms $(86 \%$; 95\% CI: 76-92; n = 84) compared with MMF farms (70\%; 95\% CI: 66-74; $\mathrm{n}=484)$. Similarly, ad libitum access to hay was more common $(P<0.001)$ for AMF farms (93\%; 95\% CI: 83-98; $\mathrm{n}=56)$ than for $\mathrm{MMF}$ farms (66\%; 95\% CI: $61-71 ; \mathrm{n}=336)$, as was ad libitum access to water (AMF: 99\%; 95\% CI: $93-100 ; \mathrm{n}=81$; MMF: $81 \%$; $95 \%$ CI: $77-85 ; \mathrm{n}=437 ; P<0.001)$. The proportion of farms allowing ad libitum access to TMR did not differ between AMF and MMF farms (58\%; 95\% CI: 47-72).

Weaning. Age was the main criterion for starting weaning calves off milk in both AMF farms $(\mathrm{n}=88)$ and MMF farms $(\mathrm{n}=521)$, although its use was greater among AMF farms (94\%; 95\% CI: 87-98) compared with MMF farms (84\%; 95\% CI: 80-87; $P=0.01$ ). The use of starter intake as a criterion for weaning was more common within MMF farms (50\%; 95\% CI: 46-55) than within AMF farms (16\%; 95\% CI: 9-25). Differences in the age at weaning and the length of the weaning period between AMF and MMF farms are shown in Table 5.

Table 5. Age at access to solid feed and water, age at weaning, and length of weaning period reported by farms using automated milk feeders (AMF) and manual milk feeding (MMF) systems from an online questionnaire completed by 670 dairy producers in Canada

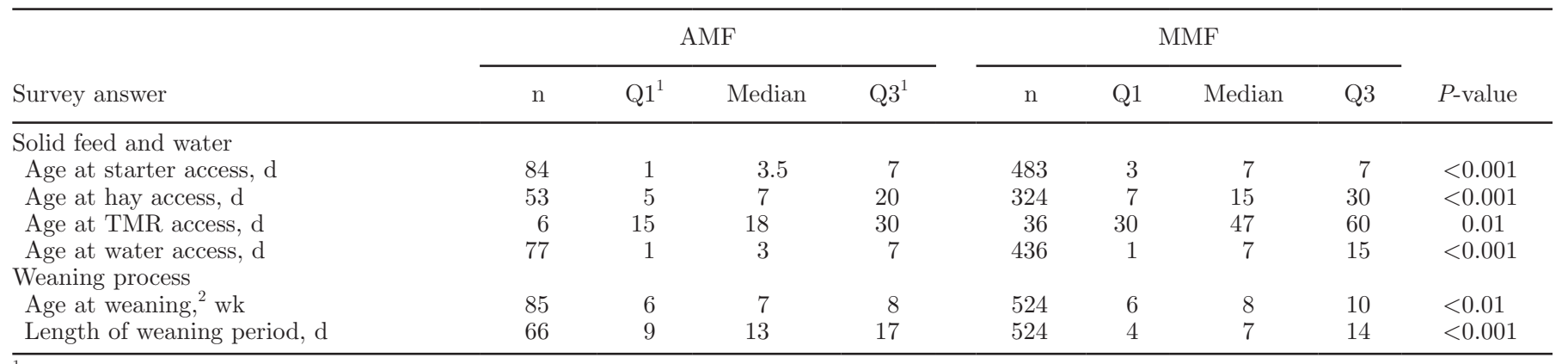

${ }^{1} \mathrm{Q} 1=25$ th percentile; $\mathrm{Q} 3=75$ th percentile.

${ }^{2}$ The beginning of the weaning period was defined as the day when the peak of milk offered to calves started to be decreased. 
There was a difference $(P<0.001)$ in the method of weaning between AMF and MMF farms. Gradual weaning was used on all AMF farms and on $85 \%$ of MMF farms (95\% CI: $82-88$ ), indicating that $15 \%$ of MMF farms used abrupt weaning. Gradual weaning was mainly done by progressively reducing the volume of milk offered to calves (instead of diluting it with water) on all AMF farms and on $75 \%$ of MMF farms (95\% CI: 71-80).

\section{Personnel in Charge of Calf Care}

The proportion of farms that reported having 1 person designated for the care of milk-fed calves tended to be larger $(P=0.07)$ among AMF farms $(28 \%$; $95 \%$ CI: $19-39 ; \mathrm{n}=86)$ compared with MMF farms $(18 \% ; 95 \%$ CI: $15-22 ; \mathrm{n}=503)$. On the contrary, the proportion of farms reporting to have 3 or more personnel tended to be smaller among AMF farms (27\%; 95\% CI: 18-37) compared with MMF farms (36\%; 95\% CI: 32-40). The most common number of personnel in charge of the care of calves for both AMF and MMF farms was 2 (46\% of farms; $95 \%$ CI: 42-50). A family member was in charge of looking after the calves in both $\operatorname{AMF}(\mathrm{n}=85)$ and MMF $(\mathrm{n}=487)$ farms $(99 \%$; 95\% CI: 98-100). In a given year, personnel looking after the calves generally did not change (98\%; 95\% CI: 97-99).

Sex and age of the personnel looking after calves differed between AMF (farms: $\mathrm{n}=86$; personnel: $\mathrm{n}=177$ ) and MMF (farms: $\mathrm{n}=58$; personnel: $\mathrm{n}=164$ ) farms. $\mathrm{A}$ higher proportion $(P=0.04)$ of personnel were female on MMF farms (45\%; 95\% CI: 37-53) compared with AMF farms (33\%; 95\% CI: 27-41). The proportion of personnel under 25 years of age was higher $(P=0.01)$ among MMF farms (37\%; 95\% CI: 29-44) compared with AMF farms $(24 \%$; 95\% CI: 18-31), as was the proportion of personnel over 64 years of age (AMF: $1 \%$; 95\% CI: $0-3$; MMF: 4\%; 95\% CI: $2-9 ; P=0.03)$. In contrast, the proportion of personnel between 25 and 44 years of age was higher $(P<0.001)$ among AMF farms (47\%: 95\% CI: 40-55) compared with MMF farms (30\%; 95\% CI: 24-38). There were no differences in the level of education between AMF and MMF farms $(P=0.63)$; the higher proportion of personnel had a college degree or higher (59\%; 95\% CI: 50-61), followed by a high school diploma (37\%; 95\% CI: 32-42).

\section{DISCUSSION}

This study is the first to provide insights into calf rearing practices on a sample of farms across Canada by comparing the prevalence of procedures and routines between farms based on their calf milk feeding system. Overall, we found that $16 \%$ of participant farms in this survey used AMF. The use of AMF has increased in Canada in recent years. For example, in a survey conducted in the province of Quebec (Vasseur et al., 2010) between 2005 and 2007, no farms had adopted these devices. Another survey conducted in the province of Ontario in 2012 showed that only $3 \%$ of 890 farms used AMF (Ken Leslie, University of Guelph, Guelph, ON, Canada; personal communication). However, it is important to take into account that in the present study there was a higher proportion of farms from Ontario and western provinces compared with the target population of Canadian farms (Ontario: 48 vs. 33\%; western provinces: 23 vs. $12 \%$; Table 1) and a higher proportion of freestall barns compared with the target population ( 50 vs. $22 \%$; Table 3 ), which could have caused an overestimation of the proportion of farms using AMF.

We found that the use of AMF was more common among farms with larger herd size and farms that were already using other types of technology (i.e., AMS, automated cow brushes, and automated feed pushers). In a survey in France, farms that had adopted AMS were larger compared with the national average (77 vs. 36 dairy cows, respectively; Veysset et al., 2001), similar to what we found for AMF in Canada. However, census data of Canadian dairy farms (CDIC, 2015) and studies in the Netherlands (Steeneveld et al., 2012) looking at AMS did not show a difference in farm size compared with farms with a conventional milking system. It is also known that producers who have adopted AMS did so mainly driven by factors that were not related to profits, such as improving working environment, getting more time for family and for other business, and making a change in lifestyle (de Jong et al., 2003; Butler et al., 2012; Bergman and Rabinowicz, 2013). Although we did not gather information to show that the adoption of AMS preceded the adoption of AMF among participant farms, we speculate that producers who had already adopted AMS (and AMS had met their expectations after installation) wanted to reduce some of the workload and lack of flexibility involved in the chore of feeding milk to calves, which led them to adopt an AMF, or vice versa. In addition, we found that participants 55 years or older were less likely to use an AMF; however, this association was present only among tiestall farms. Younger people are more likely to adopt agriculture technologies (Warren, 2004), possibly, as suggested by Pierpaoli et al. (2013), because they have a "larger working horizon." It has been suggested that older producers are harder to reach and more resistant to change (Warren, 2004); thus, we could say that this might be the case for older participants from tiestall farms in the present study. However, the effect of age on the adoption of technology has been described inconsistently in the literature. Other research- 
ers have found age to be positively correlated with the use of technology; this correlation has been attributed to older farmers' greater experience and capability of recognizing the efficiency of new technology compared with younger farmers (Torbett et al., 2007; Pierpaoli et al., 2013).

We found that newborn calves were managed similarly in farms with AMF and MMF. Nonetheless, rearing practices did differ once calves were separated from the dam. Generally, calves on respondents' farms were separated from the cow before $24 \mathrm{~h}$ after birth and were fed colostrum through a teat bottle or teat bucket within $6 \mathrm{~h}$; at least $4 \mathrm{~L}$ of colostrum was fed in the first $12 \mathrm{~h}$.

Raising calves in individual pens during the milk feeding period is a standard practice in the dairy industry (Costa et al., 2016). Our study supports this finding; more than three-fourths of farms that fed milk manually housed calves individually during the milk feeding period. Similarly, Vasseur et al. (2010), Staněk et al. (2014), and Love et al. (2016) found that 87.9, $96.7 \%$, and $92.8 \%$ of farms in Quebec (Canada), Czech Republic, and California (United States), respectively, housed calves individually. However, this was not the case for farms surveyed in our study feeding milk through AMF, where all calves were housed in groups from early in life (median $=5 \mathrm{~d}$ of age). These results are similar to those reported by Endres (2016), where calves were introduced to the feeder group at $5.4 \mathrm{~d}$ of age. In contrast, we found that calves raised on MMF farms were grouped at a median age of 8 wk. Recent research has shown that when calves are group housed after 6 wk (Costa et al., 2015) or 8 wk (de Paula Vieira et al., 2010) of age they consume less solid feed and have lower weight gain and reduced performance when mixed with other calves compared with calves grouped at an early age (i.e., pair housing in the first week of life).

Group housing has been associated with a higher risk of enteric and respiratory diseases in dairy calves (Svensson et al., 2003). The size of the group, among other factors, is one of the main contributors to health issues rather than group housing per se. Keeping the size of the group small (3-8 calves) reduces the risk of illness and mortality (Svensson et al., 2003, 2006) as well as the level of competition among calves (12 vs. 24 calves; Jensen, 2004). We found that the most common group size for AMF farms was 10 to 15 calves, although $18 \%$ of farms were housing more than 16 calves per group. On the other hand, the majority of MMF farms housing calves in groups used a maximum group size of 9 ; only $2 \%$ of farms housed more than 16 calves in a group. Svensson et al. (2003) found no difference in the incidence risk of diarrhea and respiratory disease between farms housing calves individually and farms housing calves in small groups (i.e., 3-8 calves; both farms feeding milk manually). On the other hand, when comparing individually housed and manually fed calves with calves raised in large groups (i.e., 6-30 calves) and fed through an AMF, Svensson et al. (2003) found an increase in the risk of respiratory disease and the severity of diarrhea cases. In addition, Svensson and Liberg (2006) concluded that housing calves in groups of 10 or less was preferred in terms of having lower risk of respiratory disease compared with bigger groups. Based on this, the group size used in the majority of AMF farms in our study is slightly above the recommended size and could potentially affect the health and performance of calves on these farms; conversely, this may be offset by feeding greater volumes of milk.

Looking at the first month of life, which is known to be the period when calves rely mainly on nutrients from milk for maintenance of vital functions and growth (Khan et al., 2011), we found that farms using AMF fed more milk to calves than farms using MMF systems. Automated feeders allow producers to offer larger amounts of milk to each calf by providing small meals several times a day, independent of labor availability and time (Käck and Ziemerink, 2010). Producers reported a greater daily amount of milk fed to calves from wk 1 of life to the last week before weaning (AMF farms: 6-10 L; MMF farms: 6-8 L) compared with what was reported by Vasseur et al. (2010), where calves were fed 4 to $5.5 \mathrm{~L}$ of milk or milk replacer on farms in the province of Quebec, and compared with milk levels reported by Staněk et al. (2014) and Love et al. (2016). It is important to note that although we found a general increase in the levels of milk fed to calves across Canada, $25 \%$ of producers still provided restricted milk diets (i.e., $\leq 6 \mathrm{~L} / \mathrm{d}$ ) during the entire first month of life, which does not fulfil the recommendation in the Canadian Code of Practice for the Care and Handling of Dairy Cattle, which recommends a daily allowance of $20 \%$ of calves' BW in milk (NFACC, 2009).

Feeding saleable milk to calves is expensive (Godden et al., 2005), but some Canadian producers give it to calves when milk is produced over their available production quota (Vasseur et al., 2010). Nonsaleable milk is often used as an alternative (Duse et al., 2013; Love et al., 2016); however, this practice is associated with an increased risk of transmitting pathogens such as Mycoplasma spp. to calves (Butler et al., 2000). Pasteurization of nonsaleable milk is known as an effective method for destroying pathogens in milk associated with diseases during calfhood (Godden et al., 2005). Milk replacer is another alternative that has other benefits such as easy storage and the control of disease transmission (Godden et al., 2005). We found that $89 \%$ 
of AMF farms and $40 \%$ of MMF farms fed milk replacer to calves. Similarly, Endres (2016) found that $68 \%$ of AMF farms in Minnesota fed calves milk replacer. The use of nonsaleable milk as the main type of milk fed to calves was more common among MMF farms than AMF farms (20 vs. 4\%); however, pasteurization was not a common practice among MMF farms feeding nonsaleable milk (7\%). In contrast, in a recent study in California, $48 \%$ of participating farms did pasteurize nonsaleable milk (Love et al., 2016).

Farms using AMF fed milk through an artificial teat, whereas $53 \%$ of MMF farms used an artificial teat. Similarly, Staněk et al. (2014) and Love et al. (2016) found that $57 \%$ of Czech and $71 \%$ of Californian dairy farms used teats to feed milk to calves. Our findings showed a lower use of open buckets compared with producers in Quebec, where only 8\% used teat-based systems (Vasseur et al., 2010). Teat feeding is favorable for calves because they adopt a more natural position when drinking, which may aid digestion and health (Stewart, 1976; de Passillé et al., 1993; Appleby et al., 2001). In addition, teat feeding allows calves to perform sucking behavior, which they are highly motivated to do (de Passillé et al., 1993).

Weaning calves off milk at a fixed age is the most common method of weaning used across dairy farms (6-8 wk of age, Vasseur et al., 2010; 9-10 wk old, Staněk et al., 2014; 9 wk old, Love et al., 2016), and this was true for the surveyed farms (7-8 wk). There is a large variation in the age at which calves start consuming measurable amounts of starter (de Passillé and Rushen, 2012). For instance, calves under a high milk allowance diet $(12 \mathrm{~L} / \mathrm{d})$ consumed 200 and 1,400 g/d of starter at $55 \mathrm{~d}$ (range: $23-82$ ) and $75 \mathrm{~d}$ (range: 58-94) of age, respectively (de Passillé and Rushen, 2016). Similarly, calves allowed to drink $6 \mathrm{~L}$ of milk/d consumed 2,000 $\mathrm{g} / \mathrm{d}$ at $76 \mathrm{~d}$ of age (range: 45-98; Roth et al., 2009). Therefore, weaning at a fixed age might impair the welfare of calves that might not be ready to be weaned. Weaning based on starter intake is an alternative and is one of the advantages of using an automated grain feeder in combination with an AMF (de Passillé and Rushen, 2016); however, it is still not widely used.

Reduction in labor has been identified as one of the reasons for adopting AMF in the United States (Endres, 2016). However, we found that the most common number of personnel looking after calves in both MMF and AMF farms was 2 people, and the proportion of farms with 3 or more people working in the calf barn tended to be higher among MMF farms. As such, the use of AMF could potentially imply a reduction in labor force, as has been the case for AMS (Jacobs and Siegford, 2012).
One limitation of this study is that the way participants were recruited could have led to different types of selection bias. The fact that this survey was available to dairy producers only via the Internet and that it was voluntary could have potentially led to nonresponse bias by excluding participation of producers who had limited or no access to the Internet or who were not interested in participating. This type of bias could have caused a deviation of our estimates from the true values in the target population (i.e., all Canadian dairy farms). Nonetheless, when comparing participant characteristics with data on nonparticipant characteristics extracted from incomplete surveys (i.e., age, sex, barn type, milking system, farm size, and region), we did not find any differences. In contrast, when comparing our study population with the target population (Tables 1,2 , and 3), we had higher representation of producers in Ontario and western provinces, which led to a lower percentage of tiestall farms compared with the national average. This may limit the generalizability of our results.

In addition, social desirability bias may have been introduced via respondents tailoring their answers toward what they think researchers would find acceptable. Nevertheless, producers were also aware that the survey was anonymous and that there was no risk of identifying individuals. Further, it was not possible to cover in detail every different type of milk feeding system (e.g., the use of nurse cows by some organic farmers); therefore, some producers might have felt excluded while completing the questionnaire and thus give up completing the survey. Another issue with collecting data through an online survey is that producers could have misinterpreted the questions, although the questionnaire was pretested within the target population.

\section{CONCLUSIONS}

The present study described the main differences between AMF and MMF farms regarding feeding and management practices for raising dairy calves. Farms with AMF were larger and used more automation. The AMF farms provided more milk to calves and housed them in groups from early in life, whereas the majority of MMF farms housed calves individually. The adoption of AMF potentially allows for improved animal welfare through social housing of calves and increased access to more milk. Nevertheless, the risks of increased incidence of disease in calves when large groups are used cannot be ignored. Data on housing and milk feeding management practices in this study might help guide the focus of future research and knowledge and 
technology transfer outreach to bridge the gap between understanding and adopting science-based recommendations on calf care by dairy producers.

\section{ACKNOWLEDGMENTS}

This research was funded by Dairy Farmers of Canada (Ottawa, ON, Canada) as part of the Dairy Research Cluster program. The first author thanks the Administrative Department of Science, Technology and Innovation-Colciencias (Bogota, Cundinamarca, Colombia) for the $\mathrm{PhD}$ scholarship granted. The authors also thank the following individuals who helped create the survey questionnaire: research experts Jan Ziemerink (Förster-Technik North America, Cambridge, ON, Canada), Ken Leslie (University of Guelph, Guelph, ON, Canada), Ann Godkin and Neil Anderson (Ontario Ministry of Agriculture, Food and Rural Affairs, Elora, ON, Canada), Elsa Vasseur (McGill University, SaintAnne-de-Bellevue, QC, Canada), and Nelson Dinn (University of British Columbia, Agassiz, BC, Canada); students Hana Brown, Craig LeRoy, and Jessie Hubbs (University of Guelph, Guelph, ON, Canada); and dairy producers Evan Eckert (Eckerlea Acres, Seaforth, Ontario, Canada), Tim May (Mayhaven Farms, Rockwood, Ontario, Canada), Todd Nixon (Alexerin Dairy Inc., Manotick, Ontario, Canada), Rob Vanden Hengel (Vinselaar Holsteins Inc., Seaforth, Ontario, Canada), and Philip Armstrong (Armstrong Manor Farm, Caledon, Ontario, Canada). Special thanks to Richard Cantin (CanWest DHI, Guelph, ON, Canada), Daniel Lefebvre and Steve Adam (Valacta, Sainte-Anne-deBellevue, QC, Canada), Shelley Crabtree (Dairy Research Cluster, Ottawa, ON, Canada), Sharon Laidlaw (Milk Producer Magazine, Mississauga, ON, Canada), and the Ontario Veterinary College marketing communications team for collaborating with the distribution of the survey; to William Sears for his guidance with SAS; and to the dairy producers who participated in the survey and made this study possible.

\section{REFERENCES}

Abramson, J. H. 2011. WINPEPI updated: Computer programs for epidemiologists, and their teaching potential. Epidemiol. Perspect. Innov. 8:1.

Appleby, M. C., D. M. Weary, and B. Chua. 2001. Performance and feeding behaviour of calves on ad libitum milk from artificial teats. Appl. Anim. Behav. Sci. 74:191-201.

Bergman, K., and E. Rabinowicz. 2013. Adoption of automatic milking systems by Swedish milk producers. AgriFood Economics Centre working paper 7. Accessed May 2, 2016. http://www.agrifood. se/Files/AgriFood_WP20137.pdf.

Borderas, T. F., A. M. B. de Passillé, and J. Rushen. 2009. Feeding behavior of calves fed small or large amounts of milk. J. Dairy Sci. 92:2843-2852. https://doi.org/10.3168/jds.2008-1886.
Butler, D., L. Holloway, and C. Bear. 2012. The impact of technological change in dairy farming robotic milking systems and the changing role of the stockperson. Accessed Jan. 31, 2016. http://www2.hull. ac.uk/science/pdf/gees_Robotic\%20milking\%20published\%20 in $\% 20 \mathrm{jnl} \% 20 \mathrm{of} \% 20 \mathrm{RASE} . \mathrm{pdf}$.

Butler, J. A., S. A. Sickles, C. J. Johanns, and R. F. Rosenbusch. 2000. Pasteurization of discard mycoplasma mastitic milk used to feed calves: Thermal effects on various mycoplasma. J. Dairy Sci. 83:2285-2288. https://doi.org/10.3168/jds.S0022-0302(00)751149.

CDIC. 2011. Canadian Dairy Information Centre. Dairy facts and figures. The farm. Employment at the farm: Dairy farm operators. Accessed Nov. 30, 2015. http://www.dairyinfo.gc.ca/index_e. php?s1=dff-fcil\&s2 $=$ farm-ferme\&s3=impact\&s4 $=2011$.

CDIC (Canadian Dairy Information Centre). 2015. Dairy facts and figures. The farm: Types of dairy barns. Accessed Nov. 30, 2015. http://www.dairyinfo.gc.ca/index_e.php?s1=dff-fcil\&s2=farmferme\&s3 $=$ db-el.

Costa, J. H. C., R. K. Meagher, M. A. G. von Keyserlingk, and D. M. Weary. 2015. Early pair housing increases solid feed intake and weight gains in dairy calves. J. Dairy Sci. 98:6381-6386. https:// doi.org/10.3168/jds.2015-9395.

Costa, J. H. C., M. A. G. von Keyserlingk, and D. M. Weary. 2016. Invited review: Effects of group housing of dairy calves on behavior, cognition, performance, and health. J. Dairy Sci. 99:2453-2467. https://doi.org/10.3168/jds.2015-10144.

Davis Rincker, L. E., M. J. VandeHaar, C. A. Wolf, J. S. Liesman, and L. T. Chapin., and M. S. WeberNielsen. 2011. Effect of intensified feeding of heifer calves on growth, pubertal age, calving age, milk yield, and economics. J. Dairy Sci. 94:3554-3567. https://doi. org/10.3168/jds.2010-3923.

de Jong, W., A. Finnema, and D. J. Reinemann. 2003. Survey of management practices of farms using automatic milking systems in North America. Accessed Dec. 1, 2015. http://www. uwex.edu/uwmril/pdf/RoboticMilking/03_ASAE_033018_ SurveyManagementPractices.pdf.

de Passillé, A. M., and J. Rushen. 2012. Adjusting the weaning age of calves fed by automated feeders according to individual intakes of solid feed. J. Dairy Sci. 95:5292-5298. https://doi.org/10.3168/ jds.2012-5521.

de Passillé, A. M., and J. Rushen. 2016. Using automated feeders to wean calves fed large amounts of milk according to their ability to eat solid feed. J. Dairy Sci. 99:3578-3583. https://doi.org/10.3168/ jds.2015-10259.

de Passillé, A. M. B., R. Christopherson, and J. Rushen. 1993. Nonnutritive sucking by the calf and postprandial secretion of insulin, CCK, and gastrin. Physiol. Behav. 54:1069-1073. https://doi. org/10.1016/0031-9384(93)90326-B.

de Paula Vieira, A., M. A. G. von Keyserlingk, and D. M. Weary. 2010. Effects of pair versus single housing on performance and behavior of dairy calves before and after weaning from milk. J. Dairy Sci. 93:3079-3085. https://doi.org/10.3168/jds.2009-2516.

Dohoo, I., W. Martin, and H. Stryhn. 2009. Veterinary Epidemiologic Research. VER Inc., Charlottetown, Prince Edward Island, Canada.

Duse, A., K. P. Waller, U. Emanuelson, H. E. Unnerstad, Y. Persson, and B. Bengtsson. 2013. Farming practices in Sweden related to feeding milk and colostrum from cows treated with antimicrobials to dairy calves. Acta Vet. Scand. 55:49 https://doi. org/10.1186/1751-0147-55-49.

Endres, M. I. 2016. Is automated calf feeding right for your farms? Pages 233-241 in Proc. Western Canadian Dairy Symposium, Red Deer, Alberta, Canada. Accessed Dec. 21, 2015. http://www.wcds. ca/proc/2016/Manuscripts/p\%20233\%20-\%20244\%20Endres.pdf.

Gelsinger, S. L., A. J. Heinrichs, and C. M. Jones. 2016. A metaanalysis of the effects of preweaned calf nutrition and growth on first-lactation performance. J. Dairy Sci. 99:6206-6214. https:// doi.org/10.3168/jds.2015-10744.

Godden, S. M., J. P. Fetrow, J. M. Feirtag, L. R. Green, and S. J. Wells. 2005. Economic analysis of feeding pasteurized nonsaleable milk versus conventional milk replacer to dairy calves. J. 
Am. Vet. Med. Assoc. 226:1547-1554. https://doi.org/10.2460/ javma.2005.226.1547.

Jacobs, J. A., and J. M. Siegford. 2012. Invited review: The impact of automatic milking systems on dairy cow management, behavior, health, and welfare. J. Dairy Sci. 95:2227-2247.

Jensen, M. B. 2003. The effects of feeding method, milk allowance and social factors on milk feeding behaviours and cross-sucking in group housed dairy calves. Appl. Anim. Behav. Sci. 80:191-206. https://doi.org/10.1016/S0168-1591(02)00216-2.

Jensen, M. B. 2004. Computer-controlled milk feeding of dairy calves: The effects of number of calves per feeder and number of milk portions on use of feeder and social behavior. J. Dairy Sci. 87:34283438. https://doi.org/10.3168/jds.S0022-0302(04)73478-5.

Jensen, M. B., L. R. Duve, and D. Weary. 2015. Pair housing and enhanced milk allowance increase play behavior and improve performance in dairy calves. J. Dairy Sci. 98:2568-2575. https://doi. org $/ 10.3168 /$ jds.2014-8272.

Jensen, M. B., and D. Weary. 2013. Group housing and milk feeding of dairy calves. Pages 179-189 in Proc. Western Canadian Dairy Symposium, Red Deer, Alberta, Canada. Accessed Dec. 21, 2015. http://www.wcds.ca/proc/2013/Manuscripts/p\%20179\%20-\%20 $192 \%$ 20Jensen.pdf.

Käck, M., and J. Ziemerink. 2010. Benefits, function and operation of computer-controlled calf feeders. Session 4 in Proc. 1st North American Conference on Precision Dairy Management, Toronto, Ontario, Canada. Accessed Jan. 2, 2016. http://precisiondairy. com/proceedings/s4kack.pdf.

Khan, M. A., D. M. Weary, and M. A. G. von Keyserlingk. 2011. Invited review: Effects of milk ration on solid feed intake, weaning, and performance in dairy heifers. J. Dairy Sci. 94:1071-1081. https://doi.org/10.3168/jds.2010-3733.

Love, W. J., T. W. Lehenbauer, B. M. Karle, L. E. Hulbert, and R. J. Anderson. 2016. Survey of management practices related to bovine respiratory disease in preweaned calves on California dairies. J. Dairy Sci. 99:1483-1494. https://doi.org/10.3168/jds.2015-9394.

McCorquodale, C. E., A. Sewalem, F. Miglior, D. Kelton, A. Robinson, A. Koeck, and K. E. Leslie. 2013. Short communication: Analysis of health and survival in a population of Ontario Holstein heifer calves. J. Dairy Sci. 96:1880-1885. https://doi.org/10.3168/ jds.2012-5735.

Miller-Cushon, E. K., R. Bergeron, K. E. Leslie, and T. J. DeVries. 2013. Effect of milk feeding level on development of feeding behavior in dairy calves. J. Dairy Sci. 96:551-564. https://doi. org/10.3168/jds.2012-5937.

NFACC (National Farm Animal Care Council). 2009. Code of practice for the care and handling of dairy cattle. Accessed Feb. 13, 2016. http://www.nfacc.ca/codes-of-practice/dairy-cattle.

Pierpaoli, E., G. Carli, E. Pignatti, and M. Canavari. 2013. Drivers of precision agriculture technologies adoption: A literature review. Proc. Technol. 8:61-69. https://doi.org/10.1016/j. protcy.2013.11.010.

Rosenberger, K., J. H. C. Costa, H. W. Neave, M. A. G. von Keyserlingk, and D. M. Weary. 2017. The effect of milk allowance on behavior and weight gains in dairy calves. J. Dairy Sci. 100:504-512. https://doi.org/10.3168/jds.2016-11195.

Roth, B. A., N. M. Keil, L. Gygax, and E. Hillmann. 2009. Influence of weaning method on health status and rumen development in dairy calves. J. Dairy Sci. 92:645-656. https://doi.org/10.3168/ jds.2008-1153.

Soberon, F., E. Raffrenato, R. W. Everett, and M. E. Van Amburgh. 2012. Preweaning milk replacer intake and effects on long-term productivity of dairy calves. J. Dairy Sci. 95:783-793. https://doi. org/10.3168/jds.2011-4391.

Soberon, F., and M. E. Van Amburgh. 2013. Lactation biology symposium: The effect of nutrient intake from milk or milk replacer of preweaned dairy calves on lactation milk yield as adults: A metaanalysis of current data. J. Anim. Sci. 91:706-712. https://doi. org/10.2527/jas.2012-5834.

Staněk, S., V. Zink, O. Doležal, and L. Štolc. 2014. Survey of preweaning dairy calf-rearing practices in Czech dairy herds. J. Dairy Sci. 97:1-9. 10.3168/jds.2013-7325.

Steeneveld, W., L. W. Tauer, H. Hogeveen, and A. G. J. M. Oude Lansink. 2012. Comparing technical efficiency of farms with automatic milking system and a conventional milking system. J. Dairy Sci 95:7391-7398. https://doi.org/10.3168/jds.2012-5482.

Stewart, J. A. 1976. Effect of feeding calves with artificial teats at two drinking rates or by open buckets. Proc. Aust. Soc. Anim. Prod. $11: 265-267$

Svensson, C., and P. Liberg. 2006. The effect of group size on health and growth rate of Swedish dairy calves housed in pens with automatic milk-feeders. Prev. Vet. Med. 73:43-53. https://doi org/10.1016/j.prevetmed.2005.08.021.

Svensson, C., A. Linder, and S.-O. Olsson. 2006. Mortality in Swedish dairy calves and replacement heifers. J. Dairy Sci. 89:4769-4777. https://doi.org/10.3168/jds.S0022-0302(06)72526-7.

Svensson, C., K. Lundborg, U. Emanuelson, and S.-O. Olsson. 2003 Morbidity in Swedish dairy calves from birth to 90 days of age and individual calf-level risk factors for infectious diseases. Prev. Vet. Med. 58:179-197. https://doi.org/10.1016/S0167-5877(03)00046-1.

Thomas, T. J., D. M. Weary, and M. C. Appleby. 2001. Newborn and 5-week-old calves vocalize in response to milk deprivation. Appl. Anim. Behav. Sci. 74:165-173. https://doi.org/10.1016/S01681591(01)00164-2.

Torbett, J. C., R. K. Roberts, J. A. Larson, and B. C. English. 2007. Perceived importance of precision farming technologies in improving phosphorus and potassium efficiency in cotton production. Precis. Agric. 8:127-137. https://doi.org/10.1007/s11119-007-9033-1.

USDA. 2016. Dairy cattle management practices in the United States, 2014. Accessed Aug. 6, 2016. https://www.aphis.usda.gov/animal_ health/nahms/dairy/downloads/dairy14/Dairy14_dr_PartI.pdf.

Vasseur, E., F. Borderas, R. I. Cue, D. Lefebvre, D. Pellerin, J. Rushe K. M. Wade, and A. M. de Passillé. 2010. A survey of dairy calf management practices in Canada that affect animal welfare. J. Dairy Sci. 93:1307-1315. https://doi.org/10.3168/jds.2009-2429.

Veysset, P., P. Wallet, and E. Prugnard. 2001. Le robot de traite: Pour qui? Pourquoi? Caracterisation des exploitations equipees, simulations economiques et elements de reflexion avan investissement. INRA Prod. Anim. 14:51-61.

Warren, M. 2004. Farmers online: Drivers and impediments in adoption of Internet in UK agricultural businesses. J. Small Bus. Enterprise Dev. 11:371-381. https://doi.org/10.1108/14626000410551627. 